two treatment groups was evident in relation to troponin I release $(P=0.15)$. In a small subgroup of 27 patients the absolute mass of the area of hyperenhancement on cardiac MRI was significantly reduced in cyclosproin-treated patients compared with those who received placebo ( $37 \mathrm{~g}$ versus $46 \mathrm{~g}, P=0.04$ ). Cyclosporine treatment was not associated with any adverse events. The authors concluded that these promising data require validation in a large, clinical trial.

Original article Piot C et al. (2008) Effect of cyclosporine on reperfusion injury in acute myocardial infarction. $N$ Engl J Med 359: 473-481

\section{Early treatment with tirofiban improves outcomes in patients with STEMI}

A report from the Ongoing Tirofiban In Myocardial Infarction Evaluation (On-TIME 2) investigators demonstrates that patients with ST-segment elevation myocardial infarction (STEMI) benefit from early, prehospital treatment with the glycoprotein IIb/IIla inhibitor tirofiban.

This international, prospective, double-blind trial enrolled patients with acute-onset STEMI who were candidates for percutaneous coronary intervention (PCl). Participants were randomly assigned to receive a $25 \mu \mathrm{g} / \mathrm{kg}$ bolus of tirofiban with a maintenance infusion of $0.15 \mu \mathrm{g} / \mathrm{kg} / \mathrm{min}$ for $18 \mathrm{~h}(n=491)$, or matching doses of placebo $(n=493)$ at first contact with medical personnel. All patients also received aspirin, clopidogrel and unfractionated heparin. Experimental or control drugs were administered in the ambulance in $95 \%$ of cases; the median time from symptom onset to medication among these individuals was $75 \mathrm{~min}$. The mean amount of residual ST-segment elevation before (and $1 \mathrm{~h}$ after) $\mathrm{PCl}$ was significantly lower in patients assigned to tirofiban than in those who received placebo (10.9 versus $12.1 \mathrm{~mm}, P=0.028$, before $\mathrm{PCl}$ and 3.6 versus $4.8 \mathrm{~mm}, P=0.003,1 \mathrm{~h}$ after $\mathrm{PCl})$. After 30 days of follow-up, treatment with tirofiban was associated with a reduction in the combined occurrence of death, recurrent STEMI, targetvessel revascularization and emergency use of tirofiban, when compared with placebo $(26.0 \%$ versus $32.9 \%, P=0.02)$. The incidence of major bleeding did not differ significantly between the two treatment groups.

Original article van't Hof AWJ et al. (2008) Prehospital initiation of tirofiban in patients with ST-elevation myocardial infarction undergoing primary angioplasty (On-TIME 2): a multicentre, double-blind, randomised controlled trial. Lancet 372: 537-546

\section{Nonresponsiveness to dual antiplatelet therapy associated with high risk of DES thrombosis}

Thrombosis is a complication of drug-eluting stent (DES) implantation, and can occur in patients despite optimum antiplatelet therapy with aspirin and clopidogrel. Gori et al. have reported that dual nonresponsiveness to these drugs increased the risk of DES thrombosis threefold among patients in the RECLOSE trial.

This prospective study included 746 consecutive patients who received sirolimus-eluting or paclitaxel-eluting stents, and who adhered to a 6-month regimen of aspirin (325 mg daily) and clopidogrel $(75 \mathrm{mg}$ daily). Assessment of platelet reactivity revealed that $6 \%$ of patients were nonresponsive to both aspirin and clopidogrel, and that $11.5 \%$ and $6 \%$ were nonresponsive to just aspirin and just clopidogrel, respectively. After 6 months of follow-up, DES thrombosis had occurred in significantly more patients with dual nonresponsiveness than in those who were nonresponsive to just aspirin or just clopidogrel, or who responded to both drugs (11.1\% versus $2.3 \%, 2.2 \%$ and $2.1 \%$, respectively). The composite outcome of cardiac mortality and DES thrombosis was also significantly more common among individuals with dual nonresponsiveness than other patients. Multivariate analysis revealed that nonresponsiveness to both antiplatelet agents was a significant, independent predictor of DES thrombosis (hazard ratio $3.18,95 \% \mathrm{Cl}$ 1.14-8.83), and of the composite outcome of cardiac mortality and DES thrombosis (hazard ratio $2.94,95 \% \mathrm{Cl} 1.16-7.41$ ). Although rare, nonresponsiveness to dual antiplatelet therapy could be an important indicator of increased risk of DES thrombosis.

Original article Gori AM et al. (2008) Incidence and clinical impact of dual nonresponsiveness to aspirin and clopidogrel in patients with drug-eluting stents. J Am Coll Cardiol 52: 734-739 